\title{
ANTIBACTERIAL AND ANTICANCER POTENTIAL OF SILVER NANOPARTICLES SYNTHESIZED USING GALLIC ACID IN BENTONITE/STARCH BIO-NANOCOMPOSITES
}

\author{
ANUPAMA THAPLIYAL, AMRISH CHANDRA* \\ Amity Institute of Pharmacy, Amity University, Noida, India
}

Email: chandra.amrish@gmail.com

Received: 05 Jun 2018, Revised and Accepted: 26 Jul 2018

\begin{abstract}
Objective: To optimize and synthesize eco-friendly and low-cost silver nanoparticles (AgNPs) by using gallic acid (GA) reducing agent in bentonite/starch bio-nanocomposites (BNCs) for oral use and to evaluate its antibacterial and anticancer efficacy.

Methods: An artificial neural network (ANN) model was employed for the optimization and evaluate the effect of the formulation variables on the entrapment efficiency (EE) of AgNPs. The synthesized AgNPs in BNCs were characterized using UV-vis spectroscopy, energy dispersive X-ray spectroscopy (EDXA), dynamic light scattering (DLS), scanning electron microscopy (SEM), zeta potential and fourier transform infrared spectroscopy (FTIR). Elemental ion analysis was carried out using inductively coupled plasma mass spectrometry (ICP-MS). Drug release study was carried out. The antimicrobial efficacy determined by agar well diffusion method. In vitro anticancer efficacy of AgNPs in breast cancer cell line (MCF-7) by MTT assay was performed.

Results: The formation of AgNPs was confirmed by UV-vis absorbance peak shown at $412 \mathrm{~nm}$. XRD spectrum has indicated the face-centered cubic structure of the synthesized AgNPs. SEM and DLS measurements showed spherical nanoparticles with a mean size of $68.06 \pm 0.2$ nm. The negative surface zeta potential with-32 $\pm 0.25 \mathrm{mV}$ has indicated colloidal stability of nanoparticles. FTIR spectra confirmed no interaction observed between drug and excipients. AgNPs showed significant EE with $80 \pm 0.25 \%$. The synthesized AgNPs in BNCs is a potential candidate for inhibiting the growth of pathogenic bacteria and showed significant cytotoxicity against MCF-7 cancer cell line with IC $50 \mathrm{of} 160 \pm 0.014 \mu \mathrm{g} / \mathrm{ml}$.
\end{abstract}

Conclusion: The present research confirms that the green synthesized AgNPs in BNCs can be a promising antibacterial and anticancer agent regarding stability, low cost and easy preparation.

Keywords: ANN model, Gallic acid, Silver nanoparticles, Bio-nanocomposites, Entrapment efficiency, Release kinetics, Antibacterial, Cytotoxicity

(C) 2018 The Authors. Published by Innovare Academic Sciences Pvt Ltd. This is an open-access article under the CC BY license (http://creativecommons.org/licenses/by/4.0/) DOI: http://dx.doi.org/10.22159/ijap.2018v10i5.27728

\section{INTRODUCTION}

Nanomaterials are the new exciting areas of research in nanoscience and nanotechnology. Metal nanoparticles are essential materials with various incredible applications in the field of antibacterial [1], engineering, chemical, biomedicine, electronics, catalysis [2], etc., because of low cost, high-efficiency and high active performance due to the small size, large surface area, distribution, and morphology. Among various metal nanoparticles, silver nanoparticles (AgNPs) have attracted high attention in last few years due to their unique properties including antiseptic, antibacterial, anticancer, low cost, highly effective and highly thermal conductivity [3-7]. Because of their exceptional properties, AgNPs have a tremendous potential for commercial application as medical tools and healthcare products. AgNPs synthesized using various methods like physical, chemical and biological methods [8]. Due to the small size and larger surface area, AgNPs have significant antimicrobial and anticancer effect [916]. Due to these characteristics, it is essential to control the size of the AgNPs, and lack of agglomeration between particles is favourable for this purpose. Nowadays, the reduction method of the bio-nanocomposites (BNCs) has been widely used for the synthesis of AgNPs without aggregation between particles because of ease of preparation and low cost. The reducing agents have a significant role in the synthesis of AgNPs [17]. Gallic acid (GA) is a naturally occurring biological compound having reducing character, good solubility in water and anticancer activities. In recent years, BNCs have attracted more attention in the field of life science, nanotechnology, engineering, and pharmaceutical fields due to its unique properties $[18,19]$. These are a new class of nanomaterial's which contains the naturally originated biopolymers from plants, microorganism and inorganic solids on the nanometer scale [20-22] which exhibits improved structural and functional properties in comparison to conventional nanocomposites used for different applications $[22,23]$. The unique features of natural polymers such as biocompatibility and biodegradability opened new prospects for these materials in the field of nanoscience. During the synthesis of AgNPs, stabilizers play a primary role in controlling the size of particles, because smaller particles have greater antimicrobial and anticancer effect. Biodegradable polymers are used as stabilizers due to their effectiveness in preventing accumulation and precipitation of the particles provide the excellent distribution of particles. Starch is mostly used natural carbohydrate polymers reserve in comparison to other polymers because of its unique properties like biocompatibility, biodegradability, nontoxicity, low cost and easy availability [23]. Nowadays, interlayer space of claymatrix has been used for the synthesis of polymeric material and biomaterial nanoparticles because of its unique intercalation, swelling, and ion exchange properties with a significant improvement in mechanical properties $[23,17]$. Bentonite is mostly used for the synthesis of polymeric nanocomposites because of its unique characteristics. It is a naturally obtained clay mineral containing aluminum silicate. Nanoparticles located at bentonite's external space which removes the agglomeration of nanoparticles. This environment-friendly starch-bentonite BNCs was found economically attractive because of easy preparation and inexpensive reagents. Artificial neural networks (ANNs) are computer program created for optimization and evaluation of experimental and response variables [24]. Due to the solving capabilities of complex relationships between formulation and response variables, ANNs have been used as a powerful and efficient simulation modeling tool in optimization and evaluation [24-26]. ANN has attracted high attention in nanotechnology field due to optimization and evaluation with showing nonlinear relationships between the experimental output with the predictive results $[23,25,27]$. Optimization and evaluation of AgNPs using ANNs would lead to saving time and money so that the best fit optimized model can obtain for synthesis [28].

In this research, AgNPs synthesized using ANN model and evaluated the effect of formulation variables, silver nitrate $\left(\mathrm{AgNO}_{3}\right)$ concentration, starch $(\% \mathrm{w} / \mathrm{w})$, bentonite and GA concentration on 
entrapment efficiency (EE). Drug release kinetics was performed. Also, we have studied the antibacterial and anticancer potential of AgNPs against MCF-7 cancer cell line.

\section{MATERIALS AND METHODS}

\section{Materials}

$\mathrm{AgNO}_{3}, 99.8 \%$, and starch were procured from fisher scientific. Bentonite powder was bought from CDH (central drug house Pvt Ltd). GA, 98\% obtained from himedia. All chemicals were of the standard analytical grade. Double distilled water (DD-water) was used for preparing aqueous solutions. Bacterial cultures were purchased from microbial type culture collection (MTCC), an institute of microbial technology, Chandigarh. Breast cancer cell lines (MCF-7) were purchased from the national centre for cell sciences (NCCS), Pune, India.

\section{Method of AgNPs synthesis in bio-nanocomposites (BNCs)}

Firstly $\mathrm{AgNO}_{3} /$ starch colloids were prepared using different molar concentration of $\mathrm{AgNO}_{3}$, than added drop by drop to the aqueous starch solutions under continuous stirring for half an hour. Different concentrations of bentonite suspension were prepared. Then prepared $\mathrm{AgNO}_{3} /$ starch colloids were added to the bentonite suspension under constant stirring for more than $3 \mathrm{~h}$ to obtain $[\mathrm{Ag}$ (bentonite/starch)]+composites. GA aqueous solution was prepared with a molar ratio of (1:4) of $\mathrm{AgNO}_{3}$ : GA added to the [ $\mathrm{Ag}$ (bentonite/ starch)]+composites drop by drop under continuous stirring for $3 \mathrm{~h}$ to synthesize nanoparticles. The observed dark brown color of solution confirmed the formation of AgNPs. Then finally prepared AgNPs were separated by centrifugation, washed with double distilled water twice and dried under vacuum at $40{ }^{\circ} \mathrm{C}$ [23]. Bentonite suspension was used as the appropriate support for reducing $\mathrm{AgNO}_{3}$ /bentonite suspension using $\mathrm{GA}$ as the active reducing agent according to equation (1 and 2 ) as follows. The possible reaction between $\mathrm{GA}$, silver (Ag) ions and starch in the bentonite suspensions can be written as follows equations.

$$
\begin{gathered}
\mathrm{Ag}^{+}+\text {Starch }+ \text { Bentonite }=\left[\mathrm{Ag}^{0}(\text { Bentonite } / \text { starch })\right]^{+} \ldots \ldots \ldots \text { (1) } \\
\mathrm{C}_{7} \mathrm{H}_{6} \mathrm{O}_{5}+\left[\mathrm{Ag}^{0}(\text { Bentonite } / \text { starch })\right]^{+}=\mathrm{C}_{6} \mathrm{H}_{2}(\mathrm{OH})_{4} \mathrm{COOH}+ \\
{\left[\mathrm{Ag}^{0}(\text { Bentonite } / \text { starch })\right]^{+} \ldots \ldots \ldots .(2)}
\end{gathered}
$$

\section{Artificial neural network (ANN) model}

AgNPs were synthesized using a neural network model which takes a set of formulation variables dataset regarding the response variables for obtaining best fit results. Primarily it works on systematically adjusting the weights so that the neural network can predict the outcomes. In this research feed forward back propagation (FFBP) neural network was used for optimization and evaluation of AgNPs, which is a multiple-layer network with an input layer, an output layer and some hidden layers [29]. The best fit ANN model for AgNPs synthesis was taken by two statistical parameters, the minimum mean squared error (MSE) and maximum coefficient of determination $\left(\mathrm{R}^{2}\right)[23,30]$.

\section{Characterization}

\section{Ultraviolet-visible (UV-vis) spectral analysis}

UV-visible spectroscopy was used for recording the formation of AgNPs in the BNCs. Perkin-elmer lambda-750 spectrophotometer was used for recording the UV-vis spectra using a $10 \mathrm{~mm}$ path length quartz cuvette.

\section{Particle size and polydispersity index (PDI)}

Particle size and PDI of the AgNPs were measured by dynamic light scattering (DLS) technique using zetasizer (nano ZS, malvern instrument Ltd., UK), dispersed at an angle of $90^{\circ}$ at a temperature of $25^{\circ} \mathrm{C}$.

Scanning electron microscopy (SEM) and energy dispersive $x-$ ray analysis (EDXA)

The morphological shape and size of AgNPs in BNCs were observed using zeiss SEM/EDXA (Germany). The AgNPs were first sonicated for $5 \mathrm{~min}$ for uniform distribution of nanoparticles. EDXA analysis was used for the elemental identification, analysis or chemical characterization of the sample.

\section{Zeta potential determination}

The surface charge on AgNPs determined using zetasizer (nano ZS, malvern instrument Ltd., UK) at $25^{\circ} \mathrm{C}$. The zeta potential determines the colloidal stability of particles.

\section{Fourier transform infrared (FTIR) analysis}

FTIR analysis of the AgNPs in BNCs was carried out to identify the primary functional groups of the compounds which are responsible for AgNPs synthesis and possible interactions between excipients. FTIR measurements were carried out using a shimadzu 8400S spectrophotometer by employing the $\mathrm{KBr}$ disc technique. The FTIR spectrum of the formulation was recorded at a resolution of $4 \mathrm{~cm}^{-1}$ in the transmission mode $\left(4000-440 \mathrm{~cm}^{-1}\right)$.

\section{Inductively coupled plasma mass spectrometry (ICP-MS) analysis}

It is a technique used for elemental determination of the relative efficiency for $\mathrm{Ag} / \mathrm{bentonite} \mathrm{BNCs}$. ICP-MS was used to identify the concentration of silver $(\mathrm{Ag})$ in the mother solution, during the synthesis of elemental AgNPs. The standard solution of $\mathrm{AgNO}_{3}(10$ ppm) was prepared and analyzed at 0 min before adding elemental ion. Then the reduction of $\mathrm{Ag}$ ion in the filtered solution was observed in a time-dependent manner confirming the synthesis of elemental AgNPs.

\section{Entrapment efficiency (EE) and loading efficiency (LE) of GA in AgNPs}

AgNPs ( $5 \mathrm{mg}$ ) was suspended in $5 \mathrm{ml}$ of ethanol, and the mixture was sonicated for $5 \mathrm{~min}$ to allow complete solubilization of particles. The resulting solution was then filtered through a $0.22-\mu \mathrm{m}$ filter and assayed spectrophotometrically at $270 \mathrm{~nm}$ [31]. The formula no. (3 and 4) then calculates the percentage drug entrapment efficiency (\%DEE) and percentage drug loading efficiency (\%DLE) respectively,

$$
\begin{aligned}
& \% \mathrm{DEE}=\frac{\mathrm{Xa}(\text { Experimental amount of drug loading in the nanoparticles })}{\mathrm{Xb}(\text { Theoretical drug loading in the formulation })} \times 100 \ldots \ldots(3) \\
& \% \mathrm{DLE}=\frac{\mathrm{Ma}(\text { Experimental amount of drug loading in the nanoparticles })}{\mathrm{Mb}(\text { Total Mass of the nanoparticles })} \times 100 \ldots \ldots \text { (4) }
\end{aligned}
$$

\section{In vitro drug release study}

For cancer targeted oral drug delivery system the release of the AgNPs at the target site is of great importance with minimum toxicity to normal cells. For this purpose, drug release was carried out by the dialysis bag method at a pH of the bloodstream, 7.4 and a $\mathrm{pH}$ of the cancer cells, 5 .

\section{Antimicrobial study}

AgNPs synthesized in BNCs were tested against pathogenic bacteria (Gram-positive (Staphylococcus aureus MTCC 737), Gram-negative (Escherichia coli MTCC 1687 or Pseudomonas aeruginosa MTCC 1688) and fungus (candida albicans MTCC 227) by agar well diffusion method [32]. The bacteria's were subcultured in the nutrient broth and incubated at temperature $37 \pm 0.2{ }^{\circ} \mathrm{C}$ for 24 h. Four wells of $5 \mathrm{~mm}$ diameter were punctured on pre-incubated nutrient agar plates using sterile cork borer $(0.5 \mathrm{~cm}$ diameter $)$ [33]. Different concentration of AgNPs was poured in each well of the bacterial agar plate. After kept $24 \mathrm{~h}$ incubation, the zone of inhibition with minimum inhibitory concentration (MIC) was measured using a vernier caliper. The minimum concentration of AgNPs that inhibited the growth of the pathogenic bacteria was known as the MIC [33].

\section{In vitro cytotoxicity by MTT assay}

\section{Cell lines and culture medium}

MCF-7 cancer cell line was purchased from the national centre for cell sciences (NCCS), Pune, India. Cancer cells were cultured using dulbecco's modified eagle's growth medium (DMEM)-high glucose (\#AL111, himedia) with 10\% fetal bovine serum (\#RM10432, hi media) and incubated at a temperature of $37 \pm 0.2{ }^{\circ} \mathrm{C}$ supplemented with a humidified atmosphere of $5 \% \mathrm{CO}_{2}$. MTT reagent $(5 \mathrm{mg} / \mathrm{ml}$, 
\#4060) purchased from himedia. Camptothecin (CPT \#C9911) standard drug purchased from sigma aldrich.

The cytotoxic activity of formulations against MCF-7 was determined by the MTT (3-(4,5-dimethyl-2-thiazolyl)-2,5-diphenyltetrazolium bromide) colorimetric assay [34]. The main principle of this assay is a reduction of the yellow colored water-soluble tetrazolium dye by $\mathrm{NAD}(\mathrm{P}) \mathrm{H}$ dependent oxidoreductase enzymes of viable cells, resulting in a formazan product with deep purple color [35]. The cytotoxicity assay was performed by seeding $200 \mu \mathrm{l}$ cell suspension in a 96-well plate at required cell density (20,000 cells per well) and incubated for $24 \mathrm{~h}$ at $37{ }^{\circ} \mathrm{C}$ in $5 \% \mathrm{CO}_{2}$ atmosphere [34]. MCF-7 cancer cells were treated with different concentrations of test agent AgNPs (25, 50, 100, 200 and 400 $\mu \mathrm{g} / \mathrm{ml}$ ) and incubated for $24 \mathrm{~h}$ at $37^{\circ} \mathrm{C}$ in $5 \% \mathrm{CO}_{2}$. CPT was used as a standard for maintaining a negative control (cancer cells without test compound) counterpart. After the incubation period spent media was removed and MTT reagent was added to a final concentration of 0.5 $\mathrm{mg} / \mathrm{ml}$ of total volume and incubated again. MTT reagent was removed after incubation, and then $100 \mu \mathrm{l}$ solubilized solution of dimethyl sulfoxide (DMSO) was added to the obtained purple formazan crystals for complete dissolution. The colorimetric assay is measured and recorded the absorbance at $570 \mathrm{~nm}$ using an ELISA reader [34]. The IC 50 value was determined by using a linear regression equation. The concentration of AgNPs showing 50\% inhibition of viability (IC ${ }_{50}$ values) was calculated. Cell viability and cytotoxicity percentage were determined using the following equation [36, 37]:

$$
\begin{aligned}
& \text { Cell Viability } \%=\frac{\text { Test0D }}{\text { Control OD }} \times 100 \ldots . . \\
& \text { Cytotoxicity } \%=100-\text { Viability } \% .
\end{aligned}
$$

\section{Cell morphology observation}

Morphology of cancer cell line, formulation and standard treated MCF-7 cancer cell line were observed after incubation for $24 \mathrm{~h}$ [34].
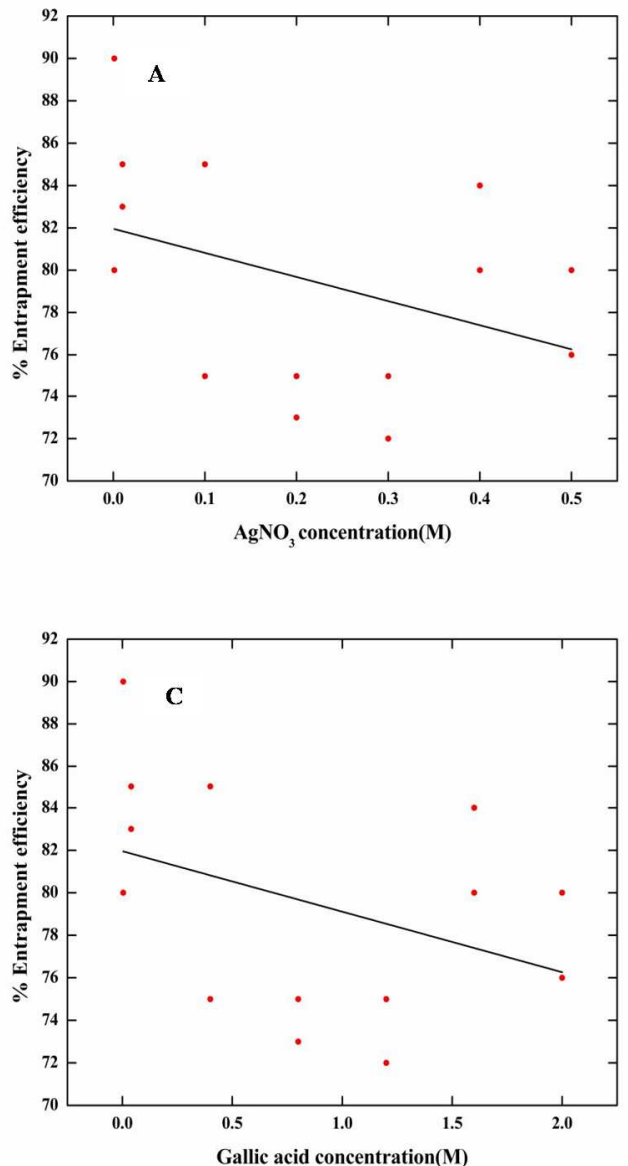

Fig. 1: 2-D linear plots effect of $\mathrm{AgNO}_{3}$ concentration (A), bentonite (g) (B), GA concentration (C) and starch (\% w/w) (D) on the \% EE

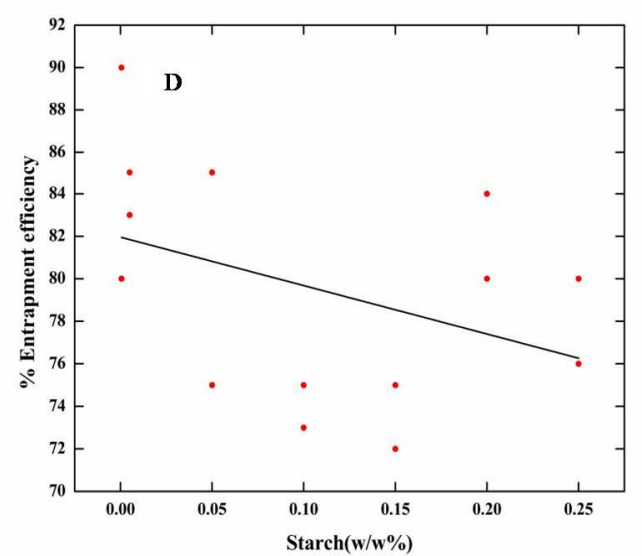

\section{Stability study}

The physical stability study was carried out to determine the temperature stability of AgNPs. For determining stability, AgNPs stored at three temperatures $\left(4{ }^{\circ} \mathrm{C}, 25^{\circ} \mathrm{C}\right.$ and $45^{\circ} \mathrm{C}$ with $\left.75 \pm 5 \% \mathrm{RH}\right)$ and observed visually for phase separation and precipitation for 6 mo as per ICH guidelines. All samples were taken out at a time intervals of $1,2,3$ and 6 mo and then evaluated for the visual inspection, particle size, zeta potential and drug content.

\section{Computation model}

AgNPs were synthesized using ANN model; MATLAB R2013a and evaluate the effects of formulation variables, $\mathrm{AgNO}_{3}$ (M), starch $(\% \mathrm{w} / \mathrm{w})$, bentonite $(\mathrm{g})$ and $\mathrm{GA}(\mathrm{g})$ regarding the response variables, $\%$ EE. Table 1 presents the experimental data of formulation variables used for the obtaining of best fit optimize ANN model for AgNPs synthesis. In this study, AgNPs were synthesized using ANN models presented with 14 prepared samples of four formulation variables $\mathrm{AgNO}_{3}$ concentration, starch $\% \mathrm{w} / \mathrm{w}$, bentonite $(\mathrm{g})$ and $\mathrm{GA}$ ). Entrapment efficiency error determined based on the difference between the predicted and the observed \%EE of these two values.

The main effects of the formulation variables on \%EE could also be explained using two-dimensional (2-D) linear plots and threedimensional (3-D) surface plots (fig. 1 and 2) respectively.

Fig. 1(A-D) represents multiple linear regression (MLR) models using 2-D plots effects of each formulation factors to response (\%EE) values. It observed that the drug entrapment efficiency increased with increased $\mathrm{AgNO}_{3}$ and $\mathrm{GA}$ concentration, starch $(\% \mathrm{w} / \mathrm{w})$ and bentonite amount.

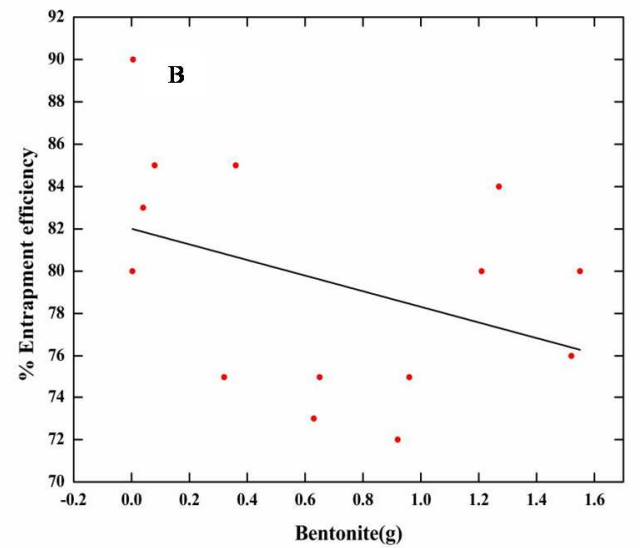

\section{RESULTS AND DISCUSSION}


Table 1: Experimental data of formulation variables used for obtaining best optimized ANN model

\begin{tabular}{|c|c|c|c|c|c|}
\hline Run no. & Starch $(\% w / w)$ & Bentonite (g) & $\mathrm{AgNO}_{3}$ con.(M) & Gallic acid con. (M) & \%Entrapment efficiency* \\
\hline 1 & 0.0005 & 0.003 & 0.001 & 0.004 & $80 \pm 0.25$ \\
\hline 2 & 0.0005 & 0.005 & 0.001 & 0.004 & $90 \pm 0.12$ \\
\hline 3 & 0.005 & 0.04 & 0.01 & 0.04 & $83 \pm 0.02$ \\
\hline 4 & 0.005 & 0.08 & 0.01 & 0.04 & $85 \pm 0.22$ \\
\hline 5 & 0.05 & 0.32 & 0.1 & 0.4 & $75 \pm 0.15$ \\
\hline 6 & 0.05 & 0.36 & 0.1 & 0.4 & $85 \pm 0.05$ \\
\hline 7 & 0.1 & 0.63 & 0.2 & 0.8 & $73 \pm 0.11$ \\
\hline 8 & 0.1 & 0.65 & 0.2 & 0.8 & $75 \pm 0.31$ \\
\hline 9 & 0.15 & 0.92 & 0.3 & 1.2 & $72 \pm 0.01$ \\
\hline 10 & 0.15 & 0.96 & 0.3 & 1.2 & $75 \pm 0.14$ \\
\hline 11 & 0.2 & 1.21 & 0.4 & 1.6 & $80 \pm 0.06$ \\
\hline 12 & 0.2 & 1.27 & 0.4 & 1.6 & $84 \pm 0.16$ \\
\hline 13 & 0.25 & 1.52 & 0.5 & 2 & $76 \pm 0.18$ \\
\hline 14 & 0.25 & 1.55 & 0.5 & 2 & $80 \pm 0.02$ \\
\hline
\end{tabular}

*Data represented as mean $\pm \mathrm{SD}(\mathrm{n}=3)$

Fig. 2(A-F) showed the 3-D effects of the four formulation variables on the $\% \mathrm{EE}$ of nanoparticles. The points in all color area (red, yellow and dark grey in fig. 2A can define that starch $(\% \mathrm{w} / \mathrm{w})$ has more effect on the $\% \mathrm{EE}$ of nanoparticles than the percentage of $\mathrm{AgNO}_{3}$. It confirms that the starch is a more significant factor which has the synergistic effect on the \%EE of the drug. In fig. $2 \mathrm{~B}$ the points in the color area (red, yellow, dark grey and sky blue) confirms the increasing percentage of the drug entrapment from nanoparticles depends on both bentonite amount and $\mathrm{AgNO}_{3}$ concentration. Fig. 2C describes that $\mathrm{GA}$ and $\mathrm{AgNO}_{3}$ concentration both are an essential factor to increase the drug entrapment efficiency. It can be attributed to the higher entrapment of the particles. Fig. 2D describes that \%EE of drug increases with increasing percentage of starch than bentonite. It confirms that polymer concentration is an essential factor for increased EE of the drug. The points located in the color area in fig. $2 \mathrm{E}$ confirm that starch and GA ratio was found to be the most significant factors on drug \% EE. The effects of GA concentration and the amount of bentonite on the \%EE of nanoparticles have shown in fig. $2 \mathrm{~F}$. The points demonstrate that the \%EE increased with increased GA than the amount of bentonite. It concludes that increased the drug concentration increased the EE. Fig. 2(A-F) confirms the more significant effects of $\mathrm{AgNO}_{3}, \mathrm{GA}$, and starch $(\% \mathrm{w} / \mathrm{w})$ compared to bentonite on the \%EE of AgNPs. The analysis concludes that \%EE of the drug increased with the concentration of $\mathrm{AgNO}_{3}, \mathrm{GA}$, and starch. It could be concluded that increasing drug and polymer ratio increased the \%EE because of the drug reached in a more viscous dispersed phase, leading to increased coalescence of the nanodroplets. It gave rise to the $\% \mathrm{EE}$ as more drugs were available for entrapment.
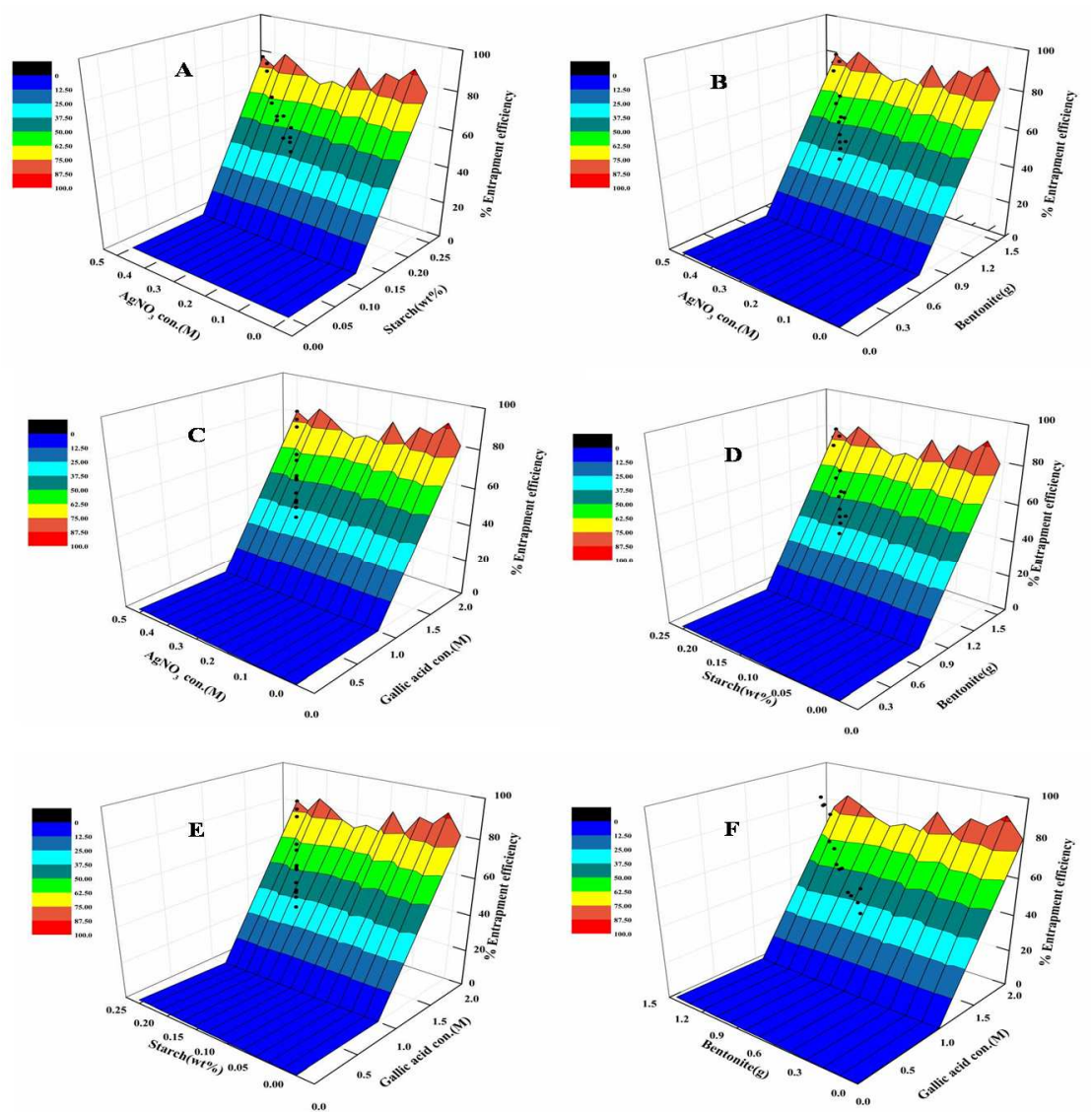

Fig. 2: Three-dimensional surfaces plots of $\mathrm{AgNO}_{3}$ concentration and \%w/w starch (A) $\mathrm{AgNO}_{3}$ concentration and bentonite(g) $(\mathrm{B}) \mathrm{AgNO}_{3}$ and GA concentration (C) \%w/w starch and bentonite (g) (D) \%w/w starch and GA concentration (E) bentonite(g) and GA concentration (F) and their effect on the \%EE 


\section{UV-absorption spectra}

The formation of AgNPs in the BNCs was confirmed by the color change of solution from light brown to dark brown. The surface plasmon resonance (SPR) bands were recorded at a wavelength of 200-800 nm. Fig. 3(A-C) presents the UV-Vis spectra of GA,
$\mathrm{Ag} /$ bentonite/starch composites and AgNPs respectively. The UV spectrum shows an absorption peak at $412 \mathrm{~nm}$, which confirmed the formation of homogenously dispersed AgNPs.

Fig. 3C indicates that the binding of GA with Ag resulted in a red shift of the absorption band of AgNPs at a higher wavelength of $412 \mathrm{~nm}$.



Fig. 3: UV-vis absorption spectra and visible observation of GA (A), Ag/bentonite/starch suspension (B) and AgNPs synthesized in $\operatorname{BNCs}(\mathrm{C})$

\section{Particle size analysis}

The particle size of AgNPs found in a range of $68-106 \pm 0.25 \mathrm{~nm}$ (mean $\pm \mathrm{SD}, n=3$ ). The PDI of nanoparticles was found between 0.2-0.8, which confirms the uniform distribution of particles. The particle size of optimized formulation was found $68.06 \pm 0.25$ with PDI $0.03 \pm 0.12$ which confirmed the uniform distribution of particles (fig. 3C).

Scanning electron microscopy (SEM) and energy-dispersive $x$ ray analysis (EDXA)

SEM determined the morphological surface, shape, and size of silver nanoparticles. Fig. 4 (A, B and C) shows that they were spherical demonstrating an average size ranging from with-in $100 \mathrm{~nm}$. EDXA spectra for the $\mathrm{Ag} / \mathrm{BNCs}$ confirmed the presence of elemental compounds in bentonite and AgNPs with no other impurity peaks (fig. 4D).

\section{The surface zeta potential}

Zeta potential study was carried out for determining the long-term stability of AgNPs and particle surface charge [23,32]. Fig. 4E indicates the zeta potential measurement of optimized AgNPs was found $-32 \pm 0.25 \mathrm{mV}$ (mean $\pm \mathrm{SD}, n=3$ ) with conductivity $4.89 \mathrm{mS} / \mathrm{cm}$ Nanoparticles with zeta potentials $>20 \mathrm{mV}$ or $<-20 \mathrm{mV}$ have been reported to remain stable in solution.
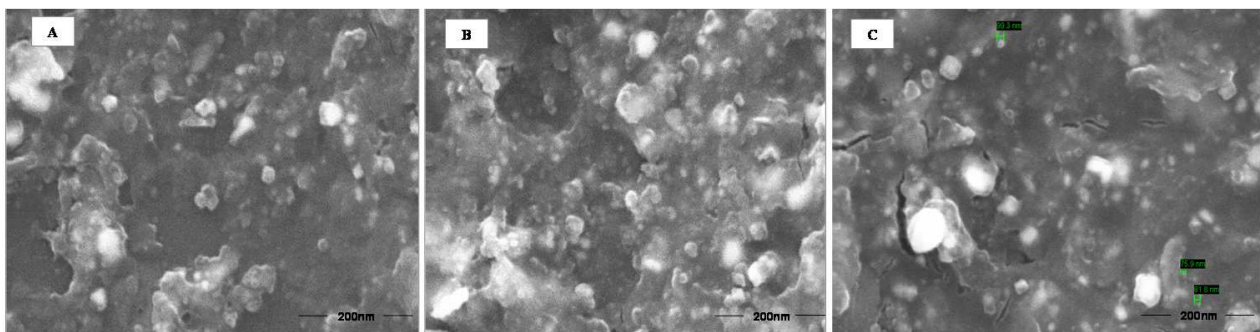

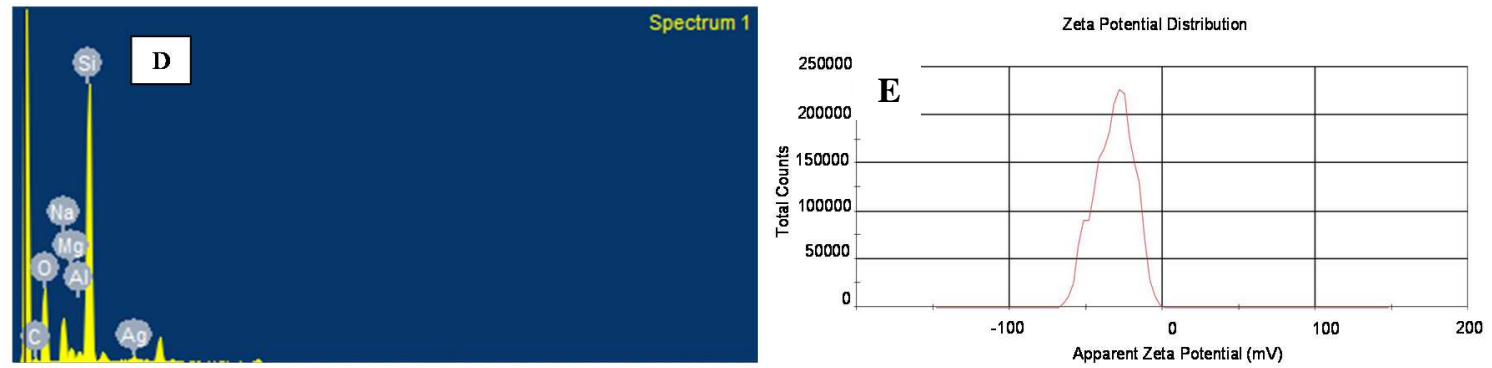

Fig. 4: SEM (A-C), EDXA (D) and zeta potential distribution (E) of AgNPs synthesized in Ag/bentonite/starch BNCs

\section{Fourier transformed infrared (FTIR) spectroscopy}

FTIR spectroscopy is used for identifying functional groups of GA, bentonite, and AgNPs or possible molecules which is responsible for the reduction of Ag ions and any interaction [37]. The FTIR spectrum of bentonite (fig. 5A) showed the vibration bands at $3622 \mathrm{~cm}^{-1}$ for 0 $\mathrm{H}$ stretching, $1631 \mathrm{~cm}^{-1}$ for $\mathrm{H}-\mathrm{O}-\mathrm{H}$ bending, $993 \mathrm{~cm}^{-1}$ for $\mathrm{Si}-\mathrm{O}$ stretching, $630 \mathrm{~cm}^{-1}$ for $\mathrm{Al}-\mathrm{OH}, 912 \mathrm{~cm}^{-1}$ due to (Al, Mg)-OH vibration modes, and $516 \mathrm{~cm}^{-1}$ for Si-O bending [38]. Fig. 5B indicates a broadband peak between 3552 and $2500 \mathrm{~cm}^{-1}$ and the narrow peak at $1772 \mathrm{~cm}^{-1}$ due to the stretching vibration of $\mathrm{O}-\mathrm{H}$ (alcohol) group and a C-0, which confirms the presence of carboxyl group in the GA. This carboxyl group binds to the surface of the AgNPs [39]. These bonds wholly disappeared after the synthesis. The absorption peak recorded at 1685, 1579, 1571 and $1481 \mathrm{~cm}^{-1}$ was assigned for vibration stretch of $\mathrm{C}-\mathrm{C}$ bonds in an aromatic group [39]. Various peaks observed in 1313$1020 \mathrm{~cm}^{-1}$ region corresponded to $\mathrm{C}-\mathrm{O}$ stretch vibration bond and bending vibration of $\mathrm{O}-\mathrm{H}$ bond of phenol GA [39]. The combination peaks present due to bentonite and the amine groups of starch confirmed in the spectrum of Ag/bentonite/starch composites (fig. 5C). The peaks of hydroxyl $(0-\mathrm{H})$ groups [17] is little shifted to low wave numbers in 3441 from $3693 \mathrm{~cm}^{-1}$ in bentonite and BNCs. The FTIR spectra of AgNPs (fig. 5D) indicate that the carbon-hydrogen $(\mathrm{C}-\mathrm{H})$ and amine $\left(-\mathrm{NH}_{2}\right)$ peaks of GA were shifted to 2881,1573 , and
$1465 \mathrm{~cm}^{-1}$ from 2968, 1685, and $1579 \mathrm{~cm}^{-1}$ which confirms the deformation of the amine group of starch. Various peaks of high and low wave numbers present due to the interactions between the silicate layers of bentonite and starch. The aliphatic $\mathrm{C}=\mathrm{H}$ stretching sharp peak corresponds to the wave number $2881 \mathrm{~cm}^{-1}$ and $\mathrm{C}=\mathrm{C}$ stretching vibration peak at $1685 \mathrm{~cm}^{-1}$. These peaks indicate the presence of alcohol and alkene groups in the GA may be involved in the reduction process to synthesize AgNPs which overlap starch peaks in 1637 and $1612 \mathrm{~cm}^{-1}$ with a bentonite peak in $1631 \mathrm{~cm}^{-1}$. The peaks present in wave number 1448,1396 , and $1342 \mathrm{~cm}^{-1}$ connected with C$\mathrm{H}$ bending, similar to the GA peaks. Various broad peaks were observed corresponds to the $\mathrm{O}-\mathrm{H}$, amine, and $\mathrm{C}-\mathrm{H}$ bending groups of GA on the surface of the AgNPs $[17,40]$. These results confirm that due to the existence of various complex peaks between the groups and AgNPs in the Ag/bentonite/GA BNCs, the peaks are shifted to low wave numbers, and the peak intensity is increased [17]. The spectrum of Ag/GA BNCs (fig. 5D) showed a blue shift of the GA peaks in 1685 and $1579 \mathrm{~cm}^{-1}$ to 1685 and $1573 \mathrm{~cm}^{-1}$, respectively. The vibration band of $\mathrm{Ag} / \mathrm{GA}$ at $1396 \mathrm{~cm}^{-1}$ could indicate the interaction between AgNPs with GA. The spectrum of Ag/starch/bentonite BNCs (fig. 5C) presented a narrower vibration band for the $0-\mathrm{H}$ group at $3441 \mathrm{~cm}^{-1}$ compared to $\mathrm{Ag} / \mathrm{GA} / \mathrm{starch} /$ bentonite composite (fig. 5D) and also the interaction peak between Ag and GA/starch at $1396 \mathrm{~cm}^{-1}$. The above results confirm that the chemical bond exists between GA molecules and Ag nanoparticles.

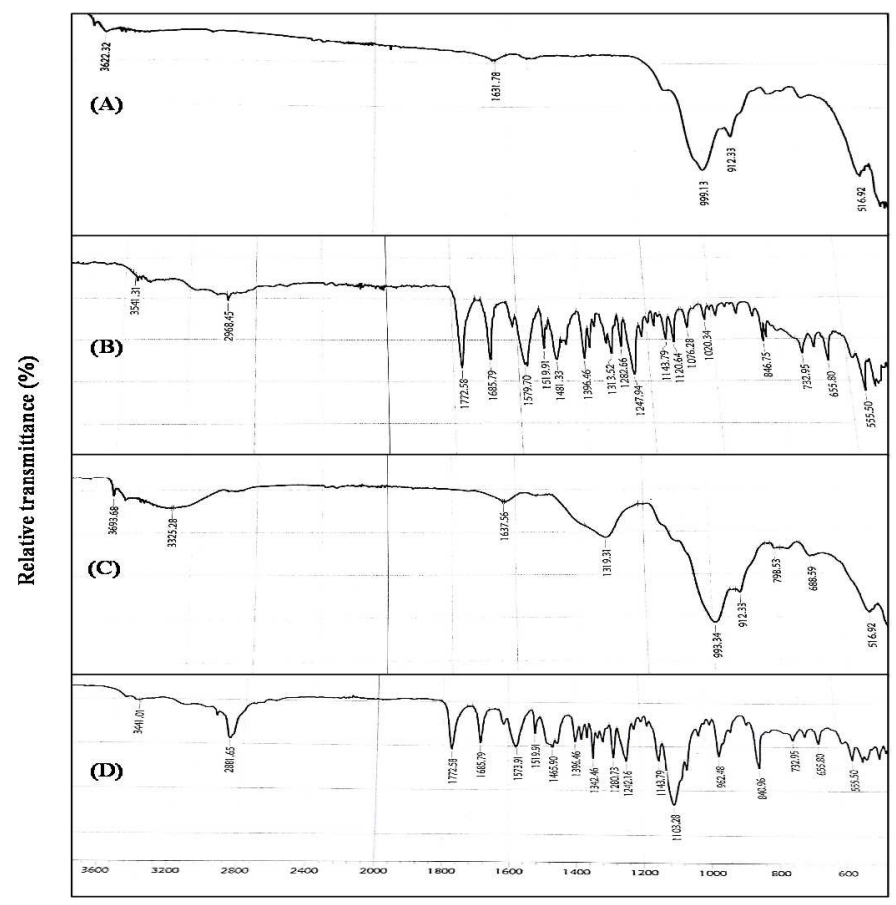

Wavenumber $\left(\mathrm{cm}^{-1}\right)$

Fig. 5: FTIR spectrum of bentonite (A) GA standard (B) Ag/bentonite/starch mixture (C) and synthesized AgNPs (D) 


\section{Inductively coupled plasma-mass spectroscopy (ICP-MS)}

The ICP-MS spectroscopy was used to determine the $\mathrm{Ag}$ ion concentration used for reduction of BNCs by GA to obtain AgNPs. Ag was measured in this solution by ICP-MS to determine the total Ag content whereas $0.72 \pm 0.02 \mathrm{ppm}$ of $\mathrm{Ag}$ was found in the nanoparticles, accounting for $64.8 \%$ of the total amount of $\mathrm{Ag}$ released from nanoparticles (fig. 6). The results from the ICP-MS analysis confirmed the formation of AgNPs in BNCs, which produced high yields.

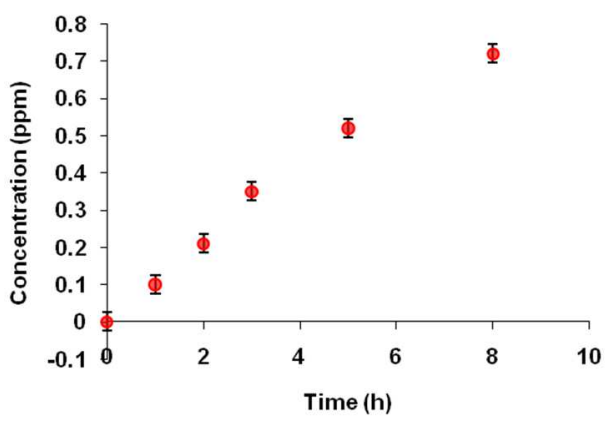

Fig. 6: ICP-MS of silver in Ag/bentonite/starch BNCs, data given as mean $\pm S D(n=3)$

\section{Drug loading and entrapment efficiency (EE) of GA in AgNPs}

The \%drug loading and \%EE in optimized AgNPs were found to be 83.5 and $80.23 \pm 0.25 \%$ (mean $\pm \mathrm{SD}, n=3$ ) respectively. It is concluded that GA was uniformly distributed throughout the nanoparticles and drug loss was minimum during the synthesis of the formulation.

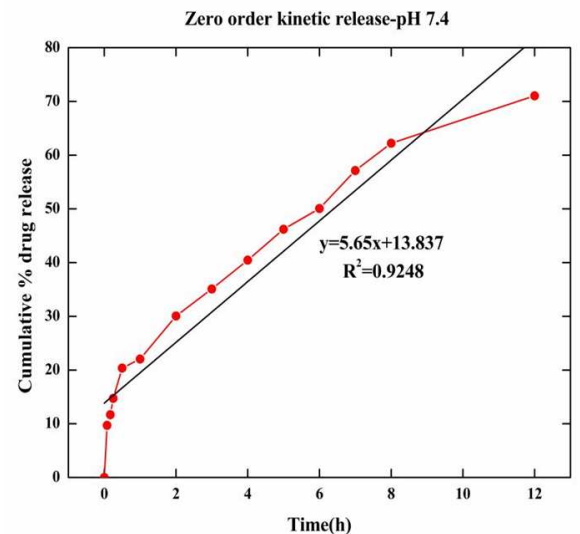

First order kinetic release-pH 7.4

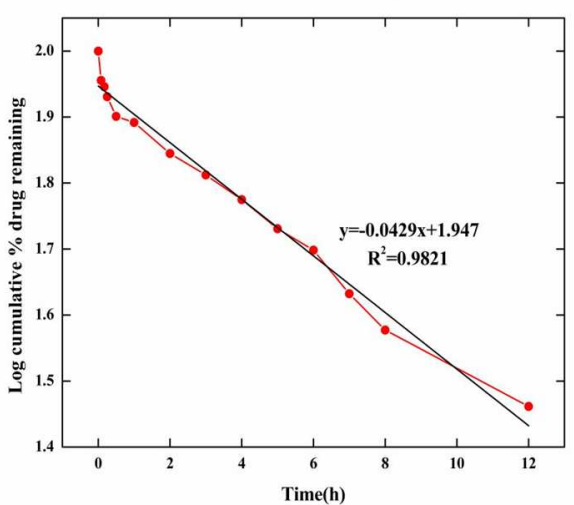

\section{In vitro release study}

Fig. 7 presents the in vitro release study of the optimized AgNPs at pH 5 and pH 7.4. It is observed that $92 \pm 0.02 \%$ drug release was achieved at cancer cells pH 5 in comparison to the $68 \pm 0.05 \%$ at $\mathrm{pH}$ 7.4 over the period of $8 \mathrm{~h}$. Optimized AgNPs showed a burst release of the drug at the initial stage and then exhibited an extended release over the $24 \mathrm{~h}$., The slowest drug release was observed at $\mathrm{pH}$ 7.4 , and the highest release was observed in $\mathrm{pH} 5$, which is the $\mathrm{pH}$ of cancer cells. It is concluded that the AgNPs can be used as an effective drug delivery system for targeting cancer because of its $\mathrm{pH}$ sensitive properties. AgNPs in BNCs system exhibit the active drug release in the acidic environment of cancer cells which increases bioavailability and therapeutic concentration of drug to cancer cells compared to healthy cells $[41,42]$.

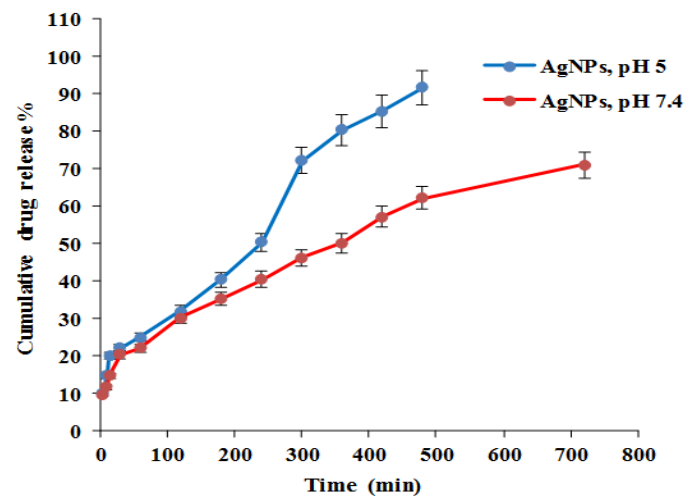

Fig. 7: In vitro release of AgNPs in $\mathrm{pH} 5$ and PBS $\mathrm{pH}$ 7.4. The values are given as mean $\pm S D(n=3)$

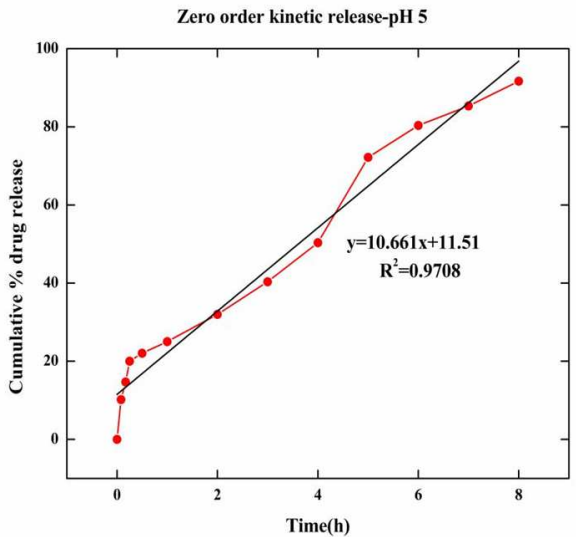

First order kinetic release-pH 5

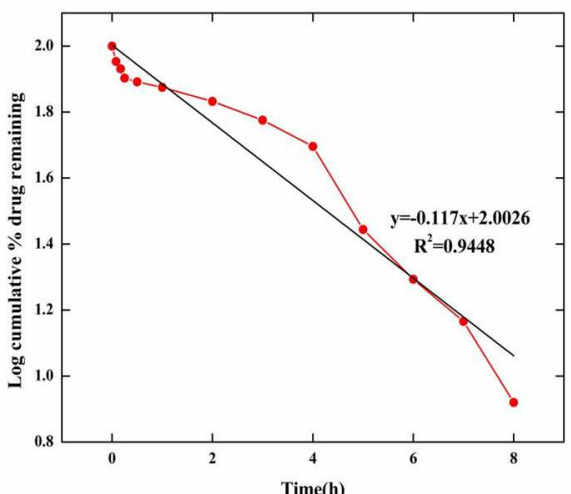



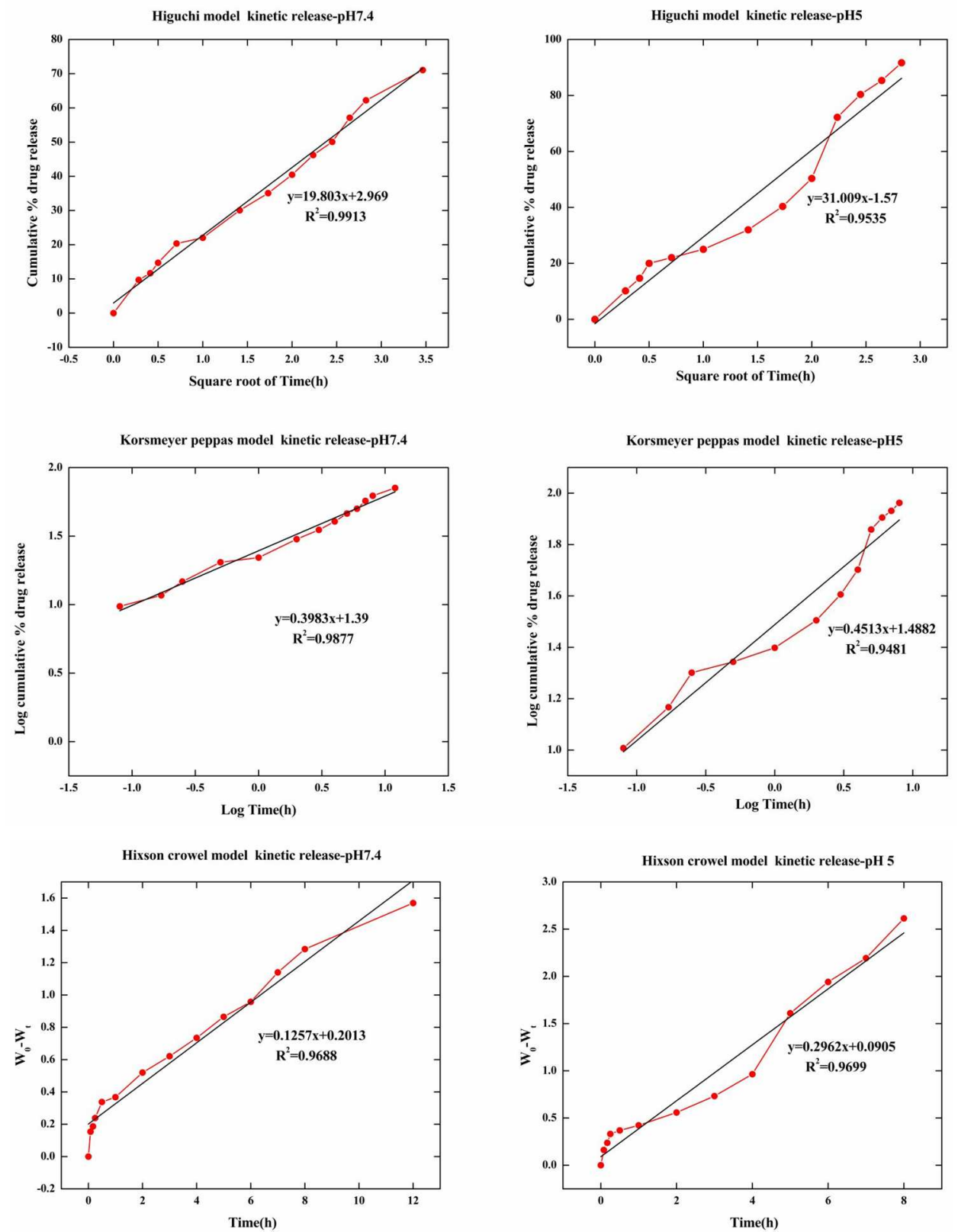

Fig. 8: Graphical representation of mechanism of drug release kinetics of optimized AgNPs for zero order, first order, higuchi, korsmeyerpeppas and hixson crowel model

\section{Release Kinetics}

To investigate the mechanism and release kinetics of drug release from AgNPs, the result of in vitro drug release data was fitted into various kinetic models like zero order (cumulative \% drug released versus time), first order (log cumulative\% drug retained versus time), higuchi (cumulative \%released versus $\sqrt{T}$ ), peppas (log of cumulative \% drug released versus log time) and hixon ( $\mathrm{W}_{0}-\mathrm{Wt}$ versus time as depicted in fig. 8. Best fit was determined. Calculate the $\mathrm{n}$ value, $\mathrm{R}^{2}$ and rate constant $(\mathrm{k})$ for each kinetic model. The best fits release kinetic model for the in vitro release data of AgNPs was determined by comparing the $\mathrm{R}^{2}$ values calculated by various models. Korsmeyer-peppas (fickian diffusion) kinetic model calculates the " $n$ " value which is known as release exponent used for describing the mechanism of drug release. Zero-order release kinetics has the " $n$ " value of 0.89 which is known as case II transport means the drug release rate is not dependent on time; $n=$ between 0.45-0.89 indicates drug release follow a first-order (non-fickian) diffusion release which is time dependent; $n=0.5$ indicates fickian diffusion release with square root of time depended, and $n>0.89$ indicates that the drug follow the super case II transport relaxation release [43]. Based on the kinetic analysis of higher $\mathrm{R}^{2}$ value it was observed that the release of drug from AgNPs at $\mathrm{pH} 7.4$ followed the higuchi kinetic model while at $\mathrm{pH} \mathrm{5,} \mathrm{the} \mathrm{zero-order} \mathrm{kinetic} \mathrm{model}$ was best predominant release mechanism fitted. The ' $n$ ' values of 1.3 and 1.5, the korsmeyer-peppas equation suggested that the drug follows the zero order release behavior which is a super case II release kinetics [44].

\section{Antibacterial activity}

Fig. 9 presents the antibacterial assay of AgNPs in BNCs against pathogenic bacterial strains (gram-positive (Staphylococcus aureus), gram-negative (Pseudomonas aeruginosa or Escherichia coli) and fungus (Candida albicans) using agar well diffusion method. The zone of inhibition is measured for each well of bacteria. Table 2 summarizes the zone of inhibition of the AgNPs samples tested against E. coli, S. aureus, P. aeruginosa and C. albicans around $8.47 \pm 0.03,9.34 \pm 0.025,8.8 \pm 0.012$ and $11.08 \pm 0.021 \mathrm{~mm}$ respectively with MICs of 5 and $6 \mathrm{ppm}$ concentration. The results indicated that 
the small size AgNPs synthesized in BNCs have promising antibacterial potential against microorganisms. Binding of AgNPs to microbial cell surface membrane depends on the surface area of nanoparticles. Small particles having a large surface area will have a potential bactericidal effect and disturb its function, such as permeability and respiration than larger particles [45].
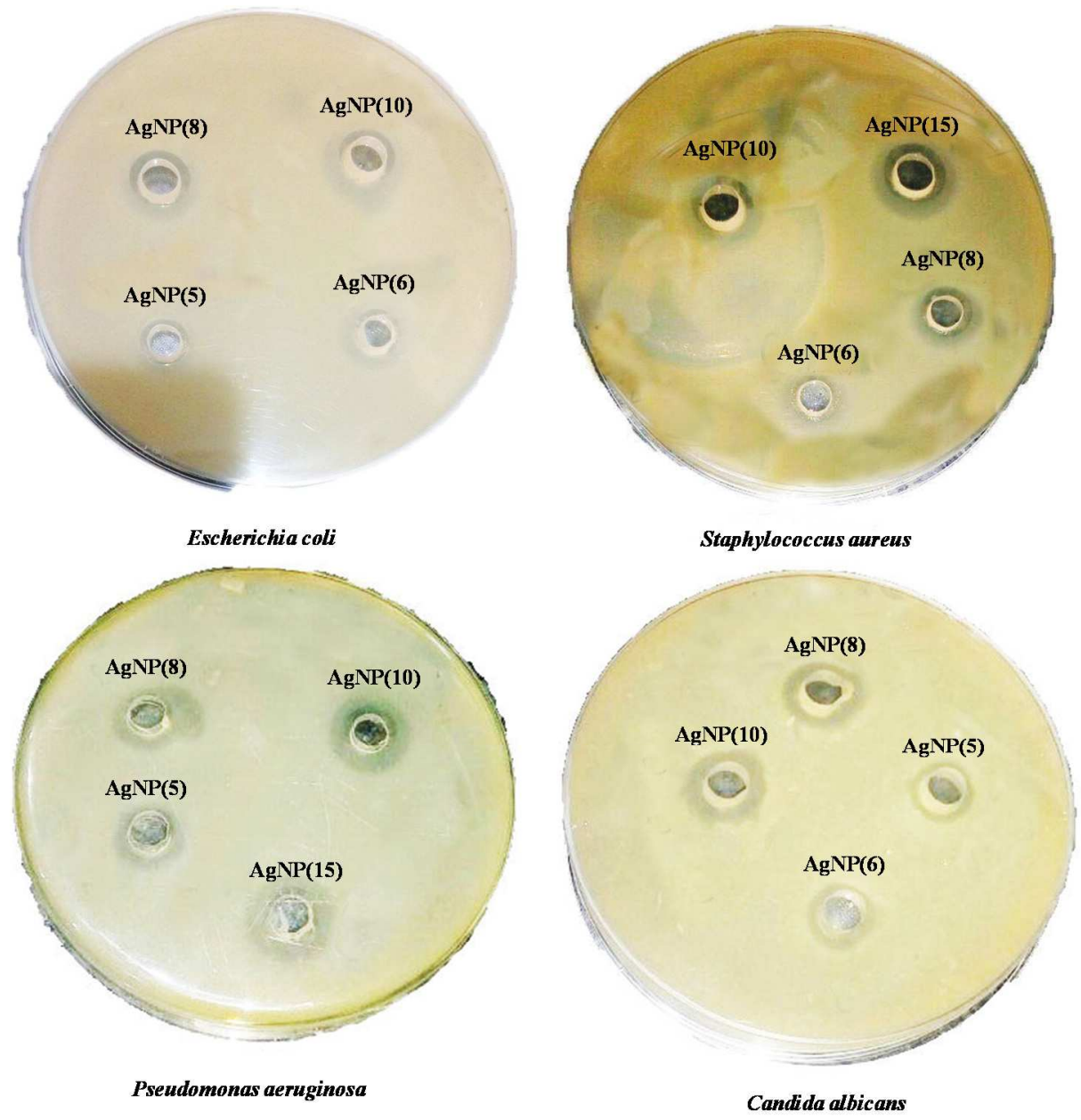

Fig. 9: Antibacterial effects of AgNPs against pathogenic bacteria, i.e., Escherichia coli, Staphylococcus aureus, Pseudomonas aeruginosa and fungus Candida albicans

Table 2: MICs with a zone of inhibition against pathogenic bacteria of AgNPs

\begin{tabular}{lll}
\hline Bacteria & Minimum inhibitory concentration(MIC) (ppm) & Zone of inhibition* (mm) \\
\hline E. coli (MTCC1687) & 5 & $8.47 \pm 0.03$ \\
S. aureus (MTCC737) & 6 & $9.34 \pm 0.025$ \\
P. s aeruginosa (MTCC1688) & 5 & $8.8 \pm 0.012$ \\
C. albicans(MTCC227) & 5 & $11.08 \pm 0.021$ \\
\hline
\end{tabular}

*Data represented as mean \pm SD $(n=3)$

\section{In vitro anticancer activity}

\section{MTT assay and cell morphology}

In this research, the MTT assay was used to evaluate the anticancer potential of AgNPs on breast cancer cell line (MCF-7) and compared with the standard anticancer drug CPT. From the MTT assay, it was determined that the cytotoxicity against breast cancer cell line increases with increasing concentration of AgNPs.

The IC 50 of AgNPs was detected at $160 \pm 0.014 \mu \mathrm{g} / \mathrm{ml}$ against the MCF-7 cancer cell lines. It concludes that $50 \%$ inhibition of cells was observed compared to untreated control (fig. 10). The proliferation of MCF-7 cancer cell line treated with AgNPs was significantly inhibited in a dose-dependent manner, concerning control cells $(p<0.001)$ and standard drug CPT $(p<0.01)$. The cytotoxic effect of synthesized AgNPs in BNCs on cancer cells was analyzed by visual inspection of the morphology of all the cells under an optical microscope.

Fig. 11(A-C) presents the morphological evaluation of control cells, the $\mathrm{IC}_{50}$ concentration of AgNPs and standard drug CPT treated cancer cells. From the morphological analysis of AgNPs treated cancer cells structural changes like cell contraction, change in cells membrane surface and inhibition of cell growth was observed. It is confirmed that apoptosis has been induced in AgNPs treated MCF-7 cancer cells $[34,35]$. 


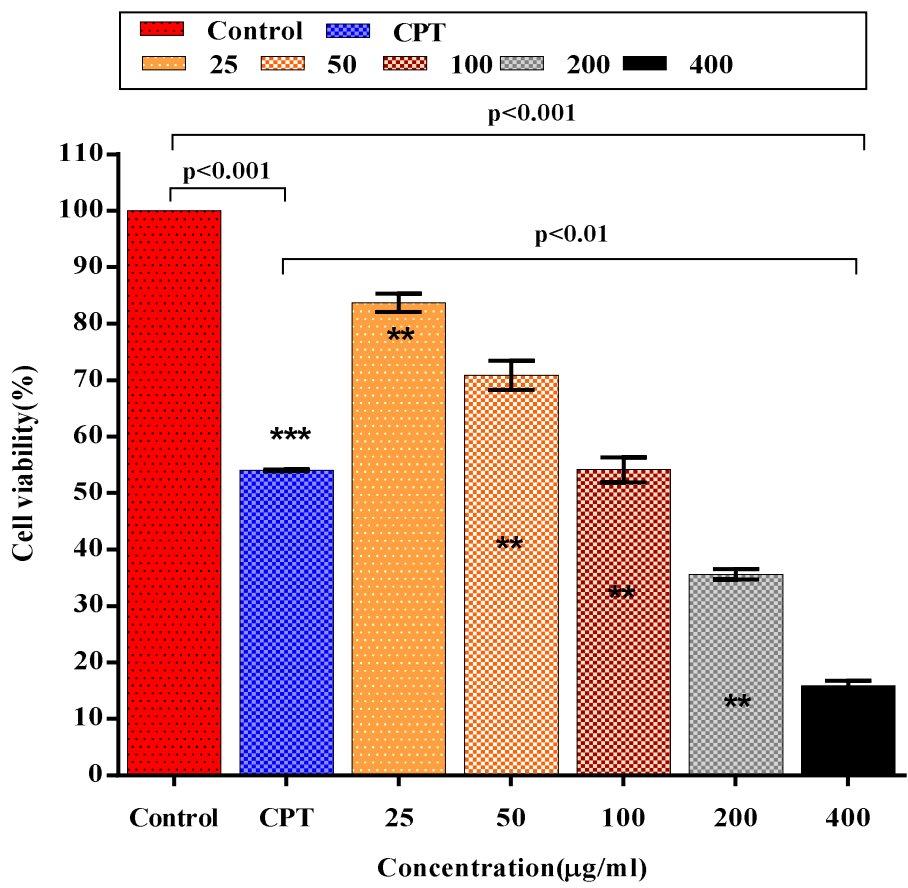

Fig. 10: In vitro anticancer activity of different concentrations of AgNPs on MCF-7 cancer cell line. CPT was used as a standard anticancer drug. Data represented as mean $\pm \mathrm{SD}(\mathrm{n}=2) .{ }^{* * *} p<0.001$ control vs. CPT. ${ }^{* * *} p<0.001$ control vs. AgNPs. ${ }^{* *} p<0.01$ AgNPs vs. CPT



Fig. 11: Morphology assessment of control (A) (IC50) AgNPs treated (B) and CPT treated MCF-7 cells (C)
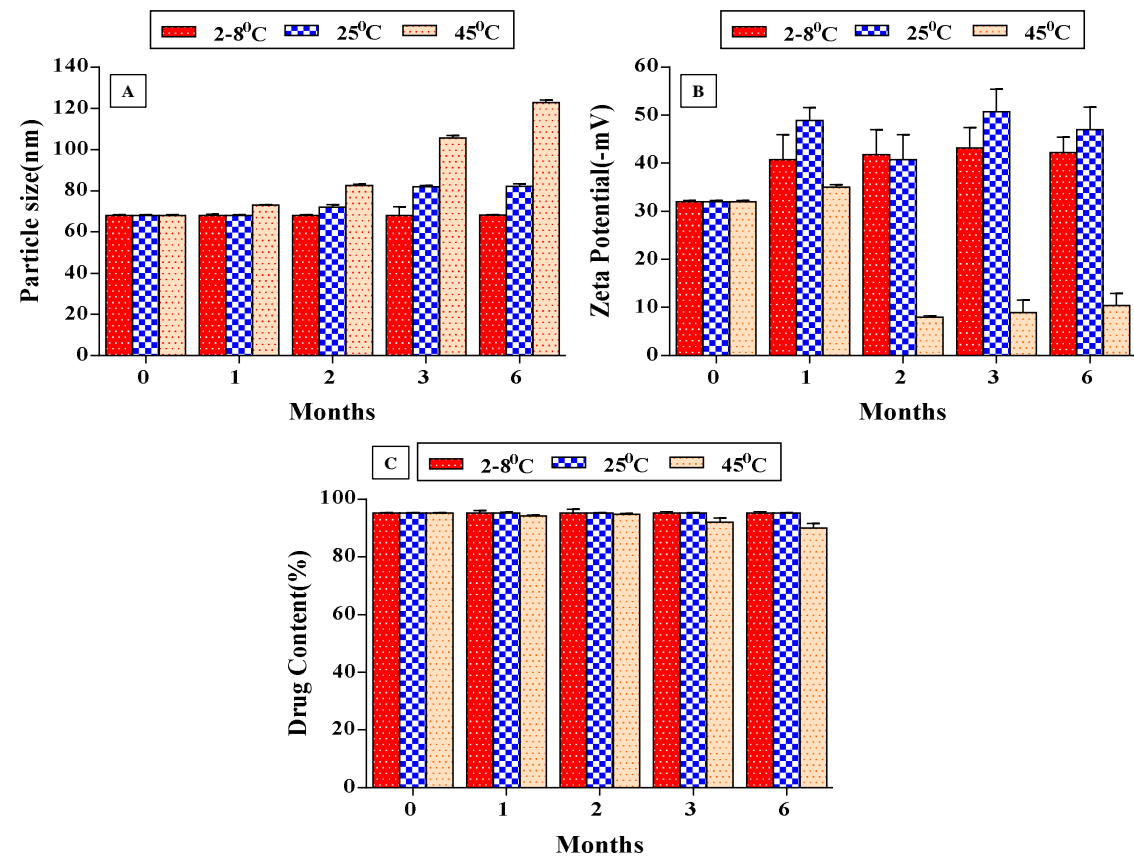

Fig. 12: The bar diagram effects of AgNPs on particle size (A), zeta potential(B) and drug content(C) at a temperature of $2-8,25$ and $45{ }^{\circ} \mathrm{C}$ during 6 mo storage, data represented as mean $\pm \operatorname{SD}(n=3)$ 


\section{Accelerated stability studies}

The macroscopic observation of AgNPs indicated no evidence of any precipitation or agglomeration observed over the period of 6 mo. The optimized AgNPs formulation was subjected to particle size analysis, zeta potential and drug content evaluation which are considered to be very critical parameters in deciding the stability of the nanoparticles. The formulation stored at $2-8{ }^{\circ} \mathrm{C}$ retained the particle size $(68.2 \pm 0.25 \mathrm{~nm})$, zeta potential $(-42.2 \pm 3.2)$ and drug content $(95.23 \pm 0.45)$ with minor variation until six mo. The formulations stored at $25{ }^{\circ} \mathrm{C}$ exhibited a slight increase in particle size $(68.06 \pm 0.25$ to $82.1 \pm 1.25 \mathrm{~nm})$ and zeta potential $(-32 \pm 0.25$ to$47 \pm 4.65)$ with a slight decrement in the drug content $(95.21 \pm 0.25)$. A considerable increase in particle size was recorded with parallel drug degradation within 6 mo. The study suggests storage in cold condition for the nanoparticles formulation, although the product is stable even above $25{ }^{\circ} \mathrm{C}$. The use of a stabilizer, starch might have played a vital role in achieving the stability of the AgNPs. The diagrammatic representation of particle size, zeta potential and drug content of AgNPs at $2-8,25$ and $45{ }^{\circ} \mathrm{C}$ during the stability period were given in fig. 12 respectively. It is concluded that AgNPs in BNCs systems is indicating good physical stability throughout the test.

\section{CONCLUSION}

In this research, biogenic AgNPs were successfully prepared from the bentonite/starch BNCs by using GA reduction at room temperature. A neural network toolbox has been used to optimize and evaluate the effects of four formulation variables, $\mathrm{AgNO}_{3}$ concentration, the weight percentage of starch, bentonite amount and GA concentration concerning the EE of AgNPs. It concludes that $\mathrm{AgNO}_{3}, \mathrm{GA}$ concentration, and the starch percentage are the crucial factors which increase the \%EE of the drug. It could be observed that increasing the amount of GA and starch increased the EE. The synthesized AgNPs was characterized using various methods. In vitro release study confirmed that AgNPs increases drug release and therapeutic efficacy of the drug in targeted cancer cells in comparison to healthy cells. AgNPs in BNCs showed significant antibacterial activity against pathogenic bacteria (gram-positive and gram-negative) and fungus. The AgNPs has confirmed the anticancer property against MCF-7 cancer cell lines which states that it can be used as anticancer drug development for further research studies. Due to the potential antibacterial and anticancer activity, it is used efficiently in the field of biology and pharmaceutical.

\section{ACKNOWLEDGMENT}

We would like to thank Amity Institute of Nanotechnology, Amity Institute of Pharmacy, Noida, India for providing an excellent research facility and environment for complete this work. Also, thanks to Jamia Millia Islamia, Centre for Nanoscience and Nanotechnology and National Research Facility (NRF) IIT Delhi, India for providing Characterization facility.

\section{AUTHORS CONTRIBUTIONS}

All authors have contributed equally

\section{CONFLICTS OF INTERESTS}

The authors report no conflict of interest

\section{REFERENCES}

1. Bhatte KD, Tambade PJ, Dhake KP, Bhanage BM. Silver nanoparticles as an efficient, heterogeneous and recyclable catalyst for synthesis of $\beta$-enaminones. Catalysis Commun 2010;11:1233-7.

2. Narayanan KB, Sakthivel N. Biological synthesis of metal nanoparticles by microbes. Adv Colloid Interface Sci 2010; 156:1-13.

3. Carotenuto G, Pepe GP, Nicolais L. Preparation and characterization of nano-sized Ag/PVP composites for optical applications. Eur Phy J B 2000;16:11-7.

4. Stathatos E, Lianos P, Falaras P, Siokou A. Photocatalytically deposited silver nanoparticles on mesoporous $\mathrm{TiO} 2$ films. Langmuir 2000;16:2398-400.

5. Kyriacou SV, Brownlow WJ, Xu XHN. Using nanoparticle optics assay for direct observation of the function of antimicrobial agents in single live bacterial cellst. Biochem 2004;43:140-7.
6. Feng $\mathrm{X}, \mathrm{Ma} \mathrm{H}$, Huang $\mathrm{S}$, Pan $\mathrm{W}$, Zhang $\mathrm{X}$, Tian $\mathrm{F}$, et al. Aqueous-organic phase-transfer of highly stable gold, silver, and platinum nanoparticles and a new route for the fabrication of gold nanofilms at the Oil/Water interface and on solid supports. J Physical Chemis B 2006;110:12311-7.

7. Choi S, Kim KS, Yeon SH, Cha JH, Lee H, Kim CJ, et al. Fabrication of silver nanoparticles via self-regulated reduction by 1-(2hydroxyethyl)-3-methylimidazolium tetrafluoroborate. Korean J Chem Eng 2007:24:856-9.

8. Mohanta YK, Nayak D, Biswas K, Singdevsachan SK, Abd Allah EF, Hashem A, et al. Silver nanoparticles synthesized using wild mushroom show potential antimicrobial activities against foodborne pathogens. Molecules 2018;23:655.

9. Zhang L, Yu JC, Yip HY, Li Q, Kwong KW, Xu AW, et al. Ambient light reduction strategy to synthesize silver nanoparticles and silver-coated TiO2 with Enhanced photocatalytic and bactericidal activities. Langmuir 2003;19:10372-80.

10. Matijevic E. Preparation and properties of uniform size colloids. Chem Mate 1993:5:412-26.

11. Nickel U, Castell A, Pöppl K, Schneider SA. Silver colloid produced by reduction with hydrazine as support for highly sensitive surface-enhanced raman spectroscopy. Langmuir 2000;16:9087-91.

12. Leopold N, Lendl BA. New method for fast preparation of highly surface-enhanced raman scattering (SERS) active silver colloids at room temperature by reduction of silver nitrate with hydroxylamine hydrochloride. J Phys Chem B 2003;107:5723-7.

13. Khanna PK, Subbarao VVVS. Nanosized silver powder via reduction of silver nitrate by sodium formaldehyde sulfoxylate in acidic $\mathrm{pH}$ medium. Mate Lett 2003;57:2242-5.

14. Sondi I, Goia DV, Matijević E. Preparation of highly concentrated stable dispersions of uniform silver nanoparticles. J Coll Int Sci 2003;260:75-81.

15. Morones JR, Elechiguerra JL, Camacho A, Holt K, Kouri JB, Ramírez JT, et al. The bactericidal effect of silver nanoparticles. Nanotechnol 2005;16:2346-53.

16. Baker C, Pradhan A, Pakstis L, Pochan DJ, Shah SI. Synthesis and antibacterial properties of silver nanoparticles.J. Nanosci Nanotechnol 2005;5:244-9.

17. Shameli K, Ahmad MB, Zargar M, Yunis WM, Ibrahim NA, Shabanzadeh P, et al. Synthesis and characterization of silver/ montmorillonite/chitosan bionanocomposites by chemical reduction method and their antibacterial activity. Int J Nanomed 2011;271-84.

18. Ahmad. Synthesis and characterization of silver/clay/chitosan bionanocomposites by uv-irradiation method. Am J Appl Sci 2009;6:2030-5.

19. Darder M, Aranda P, Ruiz-Hitzky E. Bionanocomposites: a new concept of ecological, bioinspired, and functional hybrid materials. Adv Materials 2007;19:1309-19.

20. Mallakpour S, Dinari M. Synthesis and properties of biodegradable poly (vinyl alcohol)/Organo-nanoclay bionanocomposites. J Polymers Environ 2012;20:732-40.

21. Ma X, Chang PR, Yang J, Yu J. Preparation and properties of glycerol plasticized-pea starch/zinc oxide-starch bionanocomposites. Carbohydrate Polymers 2009;75:472-8.

22. Gavade C, Shah S, Singh NL, Garg AB, Mittal R, Mukhopadhyay R. Synthesis of silver polymer nanocomposites and their antibacterial activity. AIP 2011;1349:168.

23. Shabanzadeh P, Yusof R, Shameli K. Artificial neural network for modeling the size of silver nanoparticles' prepared in montmorillonite/starch bionanocomposites. J Industrial Eng Chem 2015;24:42-50.

24. Nazari AG, Mozafari M. Simulation of structural features on the mechanochemical synthesis of Al2O3-TiB2 nanocomposite by the optimized artificial neural network. Adv Powder Technol 2012;23:220-7.

25. Shabanzadeh $\mathrm{P}$, Senu N, Shameli K, Tabar MM. Artificial intelligence in numerical modeling of silver nanoparticles prepared in montmorillonite interlayer space. J Chemistry 2013;1-8. http://dx.doi.org/10.1155/2013/305713.

26. Ozdemir U, Ozbay B, Veli S, Zor S. Modeling adsorption of sodium dodecyl benzene sulfonate (SDBS) onto polyaniline (PANI) by using multilinear regression and artificial neural networks. Chem Eng J 2011;178:183-90. 
27. Abdul Rahman MB, Chaibakhsh N, Basri M, Salleh AB, Abdul Rahman RNZR. Application of artificial neural network for yield prediction of lipase-catalyzed synthesis of dioctyl adipate. Appl Biochem Biotechnol 2009;158:722-35.

28. Khayet M, Cojocaru C, Essalhi M. Artificial neural network modeling and response surface methodology of desalination by reverse osmosis. J Membrane Sci 2011;368:202-14.

29. Shabanzadeh P, Yusof R, Shameli K. Modeling of biosynthesized silver nanoparticles in Vitex negundo L. extract by the artificial neural network. RSC Adv 2015;5:87277-85.

30. Demuth H, Beale M. Neural network toolbox for use with matlab, The Math-Works, Inc, MA; 1998.

31. Awotwe Otoo D, Zidan AS, Rahman Z, Habib MJ. Evaluation of anticancer drug-loaded nanoparticle characteristics by nondestructive methodologies. AAPS Pharm Sci Tech 2012; 13:611-22.

32. Valodkar M, Nagar PS, Jadeja RN, Thounaojam MC, Devkar RV, Thakore S. Euphorbiaceae latex-induced green synthesis of noncytotoxic metallic nanoparticle solutions: a rational approach to antimicrobial applications. Colloids Surf A 2011;384:337-44.

33. Kareem S, Akpan I, Ojo O. Antimicrobial activities of calotropisprocera on selected pathogenic microorganisms. Afr J Biomed Res 2010;11:33.

34. Uma Suganyaa KS, Govindarajua K, Ganesh Kumara D, Prabhu C, Arulvasu T, Stalin Dhasa V, et al. Anti-proliferative effect of biogenic gold nanoparticles against breast cancer cell lines (MDA-MB-231 and MCF-7). Appl Sur Sci 2016;371:415-24.

35. Mosmann T. Rapid colorimetric assay for cellular growth and survival: Application to proliferation and cytotoxicity assays. J Immunol Methods 1983;65:55-63.

36. El-Naggar NEA, Hussein MH, El-Sawah AA. Bio-fabrication of silver nanoparticles by phycocyanin, characterization, in vitro anticancer activity against breast cancer cell line and in vivo cytotoxicity. Sci Reports 2017;7:10844.
37. Theivasanthi T, Alagar M. Konjac biomolecules assisted$\mathrm{rod} / \mathrm{spherical}$ shaped lead nanopowder synthesized by an electrolytic process and its characterization studies. Nano Biomedicine Eng 2013;5:2.

38. Alemdar A, Gungor N, Ece OI, Atici O. The rheological properties and characterization of bentonite dispersions in the presence of non-ionic polymer PEG. J Materials Sci 2005;40:171-7.

39. Wang $\mathrm{W}$, Chen $\mathrm{Q}$, Jiang $\mathrm{C}$, Yang D, Liu X, Xu S. One-step synthesis of biocompatible gold nanoparticles using gallic acid in the presence of poly-(N-vinyl-2-pyrrolidone). Colloids Surf A 2007;301:73-9.

40. Shameli K, Ahmad MB, ZW Yunis WZ, Rustaiyan A, Ibrahim NA, Mohsen Z, et al. Green synthesis of silver/montmorillonite/ chitosan bionanocomposites using the UV irradiation method and evaluation of antibacterial activity. Int J Nanomed 2010;5:875-7.

41. Elbaz NM, Ziko L, Siam R, Mamdouh W. Core-shell silver/polymeric nanoparticles-based combinatorial therapy against breast cancer in vitro. Sci Reports 2016;6. Doi:10.1038/srep30729

42. Krishnaraj C, Jagan EG, Rajasekar S, Selvakumar P, Kalaichelvan PT, Mohan N. Synthesis of silver nanoparticles using Acalyphaindica leaf extracts and its antibacterial activity against water borne pathogens. Colloids Surf B 2010;76:50-6.

43. Ofokansi KC, Adikwu MU, Okore VC. Preparation and evaluation of mucin-gelatin mucoadhesive microspheres for rectal delivery of ceftriaxone sodium. Drug Dev Indus Pharm 2007;33:691-700.

44. Kuksal A, Tiwary AK, Jain NK, Jain S. Formulation and in vitro, in vivo evaluation of extended-release matrix tablet of Zidovudine: Influence of a combination of hydrophilic and hydrophobic matrix formers. AAPS PharmSciTech 2006;7:1-9.

45. Guzman M, Dille J, Godet S. Synthesis and antibacterial activity of silver nanoparticles against gram-positive and gram-negative bacteria. Nanomed: Nanotechnol Biol Med 2012;8:37-45. 